Athens Journal of Mass Media and Communications

Volume 8, Issue 2, April 2022 - Pages 79-92

\title{
Predatory Publications in the Era of the Internet and Technology: Open Access Publications are at Risk
}

\author{
By Akhilesh Kumar ${ }^{*}$,Ravi Gupta ${ }^{ \pm}$Krishna Kant Tripathi ${ }^{+}$\& \\ Rajani Ranjan Singh
}

This article is intended to highlight the issue of predatory journals and how they have been used to degrade the open-access journals to be perceived as predatory ones. Since many of the predatory journals are available for readers free of cost over the internet (which is among one of the many features of open-access journals/publications), the international wave of the scientific community against predatory journals stigmatized and victimized the entire open-access model of scientific publication to be perceived as substandard quality. This article critically analyzes the definitions of predatory journals and identified key characteristics of predatory journals. It is observed that lack of peer-review and charging high Article Processing Charges (APC) from authors are the two most common features of predatory journals, whereas open-access journals strictly adhere to peer-review criteria and have a clear guideline and information about the article processing fee. Knowingly or unknowingly, several authors mentioned that predatory journals are mostly open access, an overgeneralization of the author pay model upon which open access lies. Peer-review is an essential component of open access journals but not predatory journals; thus, considering predatory journals under the broad notion of open-access model of publication is unfair, stigmatizing and victimizing the open-access journals and keeping them at risk of degradation. Associating open-access journals with predatory ones is a nuisance as both have different aims, modus-operandi, and quality concerns. Therefore, there is a dire need to make policies to discourage predatory practices without victimizing the noble idea of open-access journals/publications.

Keywords: open access, predatory journals, article processing charges, peerreview

\section{Introduction}

Nowadays, the fascinating, relatively uncommon term "predatory publication" or "predatory journal" has become very popular among researchers across the globe. It seems it has been a big concern in research for researchers from each and every corner of the world, and surprisingly, has no universally accepted definition as yet. Predatory publications or predatory journals is an eerie term with no clear

\footnotetext{
*Assistant Professor, School of Education, Vardhman Mahaveer Open University, India.

${ }^{ \pm}$Assistant Professor, School of Science and Technology, Vardhman Mahaveer Open University, India.

${ }^{+}$Assistant Professor, Department of Education, Mizoram University, India.

*Professor, Department of Education, Dr. Shakuntala Misra National Rehabilitation University, India.
} 
defining and identifying features. It is also not clear what are the core features of a predatory journal so that it could be distinguished from a so-called legitimate journal. Discussions are ongoing on the issue of predatory journals, and as a result, the open access initiative is under question as many researchers equated these predatory journals with open-access journals just because so-called predatory journals are available over the internet free of cost for viewers and readers, like open-access journals. The objective of the present paper is to analyze the defining features of predatory journals critically and to critically examine the issue of predatory journals in the context of the open access movement. The article sheds light on how the misinterpretation of the term predatory journals has defamed open-access journals by giving prominence to so-called non-open access or the pay $\&$ access, model of the traditional journal publishing industry.

The Internet and the development of tools of information and communication technology has made it easy to share, publish, archive, and preserve the science and scientific knowledge in an easy, cost-effective way, and further, it has made scientific communication faster and easier than earlier when publications were based mainly in print media. The emergence of digitization and the internet increased the possibility of making information available to anyone, anywhere, anytime, and in any format (Swan, 2012), and as a result, the online version of a journal gradually became very popular. The open-access publication initiative is relatively young which is based on the fundamental criteria of 3F: Freedom, Flexibility \& Fairness (Swan, 2012). Its formal roots can be traced back to the beginning of the twenty-first century, which officially started in 2002 with Budapest joining in the open access initiative (Pamukcu Gunaydin and Dogan, 2015). Before moving forward to predatory journals, an overview of open access is of great worth. As noted in the policy document of UNESCO, open access is the provision of free access to peer-reviewed, scholarly, and research information to all (Swan, 2012). The policy definition of an open access publication must be freely available to all and the published content must be peer-reviewed, only then it could be considered as an open-access journal. Open accessibility and peerreview are two defining features of an open-access journal, and failing any one of which excludes an article/journal/publication to be considered as an open-access journal.

The definition of open access given by the Budapest Open Access Initiative (BOAI) is the central idea behind open access which explains:

"The public good they make possible is the worldwide electronic distribution of the peer-reviewed journal literature and completely free and unrestricted access to it by all scientists, scholars, teachers, students, and other curious minds. Removing access barriers to this literature will accelerate research, enrich education, share the learning of the rich with the poor and the poor with the rich, make this literature as useful as it can be, and lay the foundation for uniting humanity in a common intellectual conversation and quest for knowledge" (BOAI, 2002).

It is vital here to note that mere accessibility to everyone free of cost does not confirm an article/journal/publication to be called open access, rather, additionally it needs to be peer-reviewed too. Further, the open access agenda has widened its 
scope by generalizing it as Open Educational Resources (OER), Open Science, Open Innovation, and Open Data (Swan, 2012).

The open-access initiative was based on the noble idea of lifelong learning and making available scientific information to all without any restrictions (Swan, 2012) and without compromising the most important criteria of a scientific publication peer review. But, since last decade, it has been widely stigmatized and victimized by over-generalizing the concept of predatory journals to most of the open access content. As noted by Bartholomew (2014),

"While the dream of open access journals is a noble concept that was supposed to herald a revolution in scholarly publishing by making research freely accessible to anyone online, it has quickly turned into a quagmire" (Bartholomew, 2014).

Here the question arises how, when and why stigmatization and victimization of open-access articles/journals/publications took place. This stigmatization could be traced back to the very first incident found in the writings of Beall in 2010 when he prepared a list of several journals which were not following the said criteria of 'peer-review' and as felt by him, publishing sub-standard content. The librarian Jeffrey Beall at the University of Colorado-Denver first used the term predatory journals and published a list of so-called predatory journals (Beall, 2017b; Cartwright, 2016; Clark and Smith, 2015; Clemons et al., 2017; Manca et al., 2018; Masten and Ashcraft, 2016; Narimani and Dadkhah, 2017; Shamseer et al., 2017; Shyam, 2015; Xia, 2015). Beall outlined the mystery associated with open-access journals and the derailment of the peer-review process due to profitdriven publishers (Cook, 2017). After Beall's list of predatory journals, a big debate started in the scientific community on definition, features and the drawbacks of predatory journals and a wave started against journals publishing substandard or low-quality content, termed as predatory journals, which stigmatized entire groups of open-access journals. Most of the so-called predatory journals, as discussed in many contemporary scientific publications, were available for readers and viewers free of cost that were considered as open access by misinterpreting the single common feature of free availability as open access, ignoring the second most important feature of open-access articles/journals/publications which is peerreview. As a measure of quality and standard, internationally, a wave against predatory journals began based on an unclear and poorly defined term, predatory journals, which in turn made much maltreatment to the open-access articles/journals/publications due to misconception about the term open access, and many a time, was used synonymously to the predatory one. Few researchers supporting Beall presented that the open access is the root cause of development of predatory publications. For example, predatory journals were termed by Duc et al. (2020) as:

"A corrupt form of the open access model has also emerged in the form of predatory journals, which encourage authors to pay APCs for articles but do not engage in a robust review process" (Duc et al., 2020). 


\section{Literature Review}

Krawczyk and Kulczycki (2021) conducted a study titled How is Open Access Accused of Being Predatory? The Impact of Beall's Lists of Predatory Journals on Academic Publishing. The objective of this study was to explore the way by which predatory journals are characterized by researchers and academia keen about socalled predatory journals. Authors made efforts to differentiate between openaccess journals and predatory journals so that both could not be conflated with each other. Researchers collected publications on predatory journals from four databases like Web of Science, Scopus, Dimensions, and Microsoft Academic. The sample included 280 research articles on predatory publications published mainly in English. Authors reviewed each publication and used qualitative evaluation and analysis of selected articles. Researchers concluded that in all discussions on predatory journals there was a great impact of Beall, who coined the term predatory first. Researchers concluded that the characteristics of so-called predatory journals as noticed by Beall, were present in other such legitimate journals also. Finally, authors concluded that the predatory journals term is nothing but the overgeneralization of the shortcomings of some of the open-access journals to the entire open access movement has led to unjustified prejudices among the academic community towards open access. This is the first large-scale study that systematically examined how predatory publishing is defined in the literature.

\section{Methodology}

The study used qualitative method of observation and analysis of definitions of predatory journals. Ten such studies on predatory journals published between 2012 to 2021 in reputed journals served as a sample. An in-depth analysis of these articles was made to identify the characterizing features of predatory journals.

\section{Results and Discussion}

In order to understand these developments, one has to go several years back, when print media was dominant and during that time only selected publishers had the expertise of starting a journal. This monopoly was broken by online publishers who could now start journals independently (Shyam, 2015). Until 2002, prior to the open-access initiative, the scientific knowledge was available for those researchers only who could pay, or more explicitly, who can afford science and scientific knowledge; it was a costly affair and not available for those not in a position to pay for it. Further, the cost of scientific knowledge was increasing every year, making it difficult for the researchers to have cost-effective access to it. As noted by Swan, the rising cost of journal subscriptions is a major force behind the emergence of the open access movement (Swan, 2012). The idea of open access of knowledge, and subsequently open access publications, opened up avenues for researchers to get access of the scientific knowledge free of cost, bridging the gap of rich and poor in science. However, as the burning of a candle leaves some 
smoke, the idea of open access and the policies related to it was exploited by few ill-meaning publishers. Open access allowed publishers to get the publication cost from the authors in order to meet expenses associated with publication and maintenance of records so that it could be made freely available to readers and researchers and this author-pay model was exploited by several ill-meaning publishers. They started publishing low-quality content without peer-review for their own interest and income from authors, but it was not the only cause behind the emergence of poor-quality journals.

The mushrooming of several low-quality publications, especially journals, was the consequence of the system of the performance appraisal for a teacher involved in higher education. This keeps them under very high pressure to carry out a sufficient number of research projects to attract research grants and funding along with their teaching and academic activities. Teachers of higher education institutions were forced to publish their reports of research in scientific journals as evidence of research, sufficient in quantity in scientific journals. Publication in journals is directly linked to the appointment, promotion, and research grants of teachers. A teacher who is honest in his academic and teaching activities and doing his/her job honestly has no or limited opportunity to get a promotion and benefits of career advancement until there is strong evidence of research and a sufficient number of publications in journals in his/her name. In such a situation, teachers started finding out ways to get published. Traditional, so-called legitimate journals were taking longer than usual in making a decision of whether to publish or not, and publishing a research article sometimes were taking six months to 2 years, many a time, in the open-access model, they can charge a very high article processing fee proportionate with the impact factor and the H-Index of the journal. This pressure is compounded by high rejection rates at many so-called nonpredatory scientific journals (Moher and Srivastava, 2015), and as a result, several new publishers emerged providing a platform for early-career research scholars and teachers who could not afford publication in so-called renowned quality journals. Few big publication houses, controlling specifically the journal publication industry, made the scientific publication a number game like H-Index, Impact Factor, Cite Score, and so on. Responding to their number game, several new agencies also came up determining the impact factor of a journal in their own way and started providing very high impact factors to low-standard fake journals keeping authors and readers confused about which impact factor and indexing to rely upon.

Much debate took place on the issue of predatory journals (Beall, 2015), but it is equally true that predatory journals/publications have no universally accepted definition (Berger and Cirasella, 2015; Manca et al., 2018; Masten and Ashcraft, 2016) and different scientists have attached different meanings to it, largely, based on their individual judgment having a low or substandard quality. It is another issue beyond the scope of the present paper that how such substandard quality, fake journals have been assigned the International Standard Serial Number (ISSN) by the concerned agency without any quality check, and if such compromise with quality has been observed then why not have their ISSN number withdrawn? For a better understanding of the issue of predatory journals/publications, one needs to 
look at how the term predatory journals/publications has been defined and used in contemporary scientific literature. Table 1 summarizes some such definitions of predatory journals/publications used in scientific literature and the key ideas involved in identifying a predatory journal.

Table 1. Notion of Predatory Journals/Publications in the Contemporary Scientific Literature

\begin{tabular}{|c|c|c|}
\hline Researchers/Scholars & Characterizing Predatory Journals & Key Features Identified \\
\hline $\begin{array}{l}\text { Pamukcu Gunaydin and } \\
\text { Dogan (2015) }\end{array}$ & $\begin{array}{l}\text { They exploit the idea of the author-paid } \\
\text { gold model open access publishing by } \\
\text { charging a fee but not providing the } \\
\text { promised publishing services in return. } \\
\text { They do not follow accepted scholarly } \\
\text { publishing industry standards and seek } \\
\text { only to profit from author fees (Pamukcu } \\
\text { Gunaydin and Dogan, 2015). }\end{array}$ & $\begin{array}{l}\text { Article processing fee } \\
\text { Low standard } \\
\text { Not providing promised } \\
\text { services }\end{array}$ \\
\hline Clemons et al. (2017) & $\begin{array}{l}\text { So-called predatory journals are defined } \\
\text { as those that display an intention to } \\
\text { deceive authors and readers. The main } \\
\text { purpose of these journals is to profit from } \\
\text { article processing charges, and they may } \\
\text { therefore have little regard for the } \\
\text { scientific quality or integrity of the work } \\
\text { they accept (Clemons et al., 2017). }\end{array}$ & $\begin{array}{c}\text { Intention to deceive } \\
\text { authors. } \\
\text { Profit-making from } \\
\text { APC } \\
\text { No quality concerns }\end{array}$ \\
\hline $\begin{array}{l}\text { Eriksson and Helgesson } \\
\text { (2018) }\end{array}$ & $\begin{array}{l}\text { Browsing a few of the many recent } \\
\text { articles on the topic shows that the main } \\
\text { emphasis often has been on the motives } \\
\text { of journal owners: Pay- to-publish } \\
\text { journals - often known as predatory } \\
\text { journals. The other often mentioned and } \\
\text { defining characteristic is a lack of proper } \\
\text { peer review despite promises to the } \\
\text { contrary (Eriksson and Helgesson, 2018) }\end{array}$ & $\begin{array}{l}\text { Lack of proper peer } \\
\text { review } \\
\text { Pay \& publish }\end{array}$ \\
\hline Shamseer et al. (2017) & $\begin{array}{l}\text { A fundamental problem of predatory } \\
\text { journals seems to be that they collect } \\
\text { APC from authors without offering } \\
\text { concomitant scholarly peer-review } \\
\text { Additionally, they do not appear to } \\
\text { provide typical publishing services such } \\
\text { as quality control, licensing, indexing, } \\
\text { and perpetual content preservation and } \\
\text { may not even be fully open access. online } \\
\text { journals characterized as predatory, } \\
\text { which actively solicit manuscripts and } \\
\text { charge publications fees without } \\
\text { providing robust peer review and } \\
\text { editorial services (Shamseer et al., 2017) }\end{array}$ & $\begin{array}{l}\text { Article processing fee } \\
\text { No peer reviews } \\
\text { No quality controls } \\
\text { Poor editorial services }\end{array}$ \\
\hline Shyam (2015) & $\begin{array}{l}\text { These journals will claim to be indexed, } \\
\text { will have an ISSN number, and will also } \\
\text { claim to have an impact factor (not a } \\
\text { Thomas Reuter impact). The letter would } \\
\text { state rapid review and promise to publish } \\
\text { fast. The problem with these journals is } \\
\text { that they lack any organized editorial }\end{array}$ & $\begin{array}{l}\text { No organized editorial } \\
\text { process } \\
\text { Rapid review } \\
\text { Focus on Article } \\
\text { Processing Fee } \\
\text { Inferior scientific material } \\
\text { No indexing in reputed }\end{array}$ \\
\hline
\end{tabular}




\begin{tabular}{|c|c|c|}
\hline & $\begin{array}{l}\text { process and are mainly focused on the } \\
\text { article processing fees. This allows much } \\
\text { inferior scientific material to be } \\
\text { published. Also, these journals are rarely } \\
\text { indexed with standard indexing bodies } \\
\text { and thus do not show up in an online } \\
\text { search, making the article as good as non- } \\
\text { existent (Shyam, 2015) }\end{array}$ & indexes \\
\hline Manca et al. (2018) & $\begin{array}{l}\text { There is no clear consensus definition for } \\
\text { predatory publishers and journals. Such } \\
\text { journals have been referred to as low } \\
\text { quality, amateurish, and often unethical } \\
\text { academic publishing that is usually open } \\
\text { access (Manca et al., 2018). }\end{array}$ & $\begin{array}{c}\text { Low quality } \\
\text { Unethical academic } \\
\text { publication } \\
\text { Usually open access }\end{array}$ \\
\hline Ferris and Winker (2017) & $\begin{array}{l}\text { Predatory journals, or journals that charge } \\
\text { APC to authors, yet do not have the } \\
\text { hallmarks of legitimate scholarly journals } \\
\text { such as peer review and editing, Editorial } \\
\text { Boards, editorial offices, and other } \\
\text { editorial standards, pose a number of new } \\
\text { ethical issues in journal publishing (Ferris } \\
\text { and Winker, 2017). }\end{array}$ & $\begin{array}{l}\text { Charging an article } \\
\text { processing fee } \\
\text { Lack of peer review } \\
\text { Lack of editorial board }\end{array}$ \\
\hline Ferris and Winker (2017) & $\begin{array}{l}\text { Predatory journals misrepresent who they } \\
\text { are and what services they offer, } \\
\text { including not providing peer review, } \\
\text { editing, and indexing services. Their } \\
\text { websites often lack an editorial office } \\
\text { address or even contact information. } \\
\text { They lack information about the } \\
\text { academic appointments and locations of } \\
\text { the editor and Editorial Board (Ferris and } \\
\text { Winker, 2017) }\end{array}$ & $\begin{array}{l}\text { Misrepresentation of } \\
\text { identity \& services } \\
\text { Lack of peer review, } \\
\text { editing, and indexing } \\
\text { Lack of editorial office } \\
\text { Lack of information } \\
\text { about the location of } \\
\text { office and editorial board }\end{array}$ \\
\hline Xia et al. (2015) & $\begin{array}{l}\text { Many open access journals have a } \\
\text { reputation for being of low quality and } \\
\text { being dishonest with regard to peer } \\
\text { review and publishing costs. Such } \\
\text { journals are labeled predatory journals } \\
\text { (Xia et al., 2015) }\end{array}$ & $\begin{array}{c}\text { Low quality } \\
\text { Dishonesty regarding } \\
\text { peer review } \\
\text { Dishonesty regarding } \\
\text { Publication costs }\end{array}$ \\
\hline Cook (2017) & $\begin{array}{c}\text { A predatory journal is a journal that } \\
\text { bypasses the traditional peer-review } \\
\text { process and, for an article-processing } \\
\text { charge publishes any paper, often one } \\
\text { with questionable scientific value (Cook, } \\
\text { 2017). }\end{array}$ & $\begin{array}{l}\text { Bypassing peer review } \\
\text { Imposing APC }\end{array}$ \\
\hline
\end{tabular}

The critical analysis of the above ten scholarly publications provided inputs for identifying features of predatory journals. It was observed that a predatory journal imposes APC from authors, does not carry out a peer-review, and thus has faster acceptance and faster publication times with a wider reach to the audience. Some other features which were identified while analyzing the definitions of predatory journals were providing misleading information related to publisher, unreasonably high processing fees, poor indexing, and poor editorial services. Additionally, most of the authors quoted two main defining features for predatory journals: one 
of which is a provision of publication fee, and the other is lack of peer-review; but no common consensus definition was found. Let us examine both the criteria of predatory journals in the context of open access publications.

\section{The Issue of Pay \& Publish and Open Access}

The definition of predatory journals or publications is still an issue of great debate and scholars have started to question the validity of the term predatory (Eriksson and Helgesson, 2018). To date, it is not clear what is in fact meant by a predatory journal or publisher (Eriksson and Helgesson, 2018), and it is also quite fuzzy what is contained (i.e., published) within potential predatory journals (Shamseer et al., 2017). Beall (2015) mentioned that:

"By definition, predatory journals are open-access, so at first, one might conclude that they perform the awareness function well because anyone with internet access can read the articles they publish.” (Beall, 2015)

Beall's statement about feature of predatory journals as open access was reinforced by the global journal publishing industry for their own interest, creating a wave against so-called predatory journals in particular, but open access journals in general, by ignoring the fact that several times many characteristics used to identify predatory journals can be seen in the practices of established journals as well (Eriksson and Helgesson, 2018). In many of his publications, Beall has criticized the open-access model as a root cause of the spread of predatory journals which is not the case. For example, Beall mentioned that many around the world are promoting scholarly open-access publishing but turning a blind eye to the corruption the open-access publishing model has fostered (Beall, 2015). It is pertinent to mention that corruption is equally involved in the traditional model of publications of journals too, but an obsession that only traditional models of journal publication could provide quality scientific knowledge, the open-access has been labelled as the pay \& publish model and is stigmatized and perceived as a predatory one. It is beyond our understanding that promoting open access may lead to corruption in publication, but promoting subscription-based traditional publication might not lead to any corruption in publication, as if the subscription model is the only model of and guarantee of quality scientific publication. It may be noted here that quality is a very subjective term and the term is so fuzzy that quantitative obsessed researchers do not see quality even in qualitative research. Beall (2017a) further mentions,

"The open-access publishers are interested in soliciting authors' monies for publication, specifically those who have grant funding to spend on author fees." (Beall, 2017a)

Such inclination of researchers towards a subscription-based journal publication model contributed to marginalizing open-access journals from the mainstream publishing business and keeping the profit of few international publishers 
unaltered. In this context, one may note that the traditional journal publication houses are also gradually turning to the hybrid and transformative model from the subscription model and encouraging authors to get published under the openaccess model. Advocates of the subscription-based journal publication model ignored the corruption and finances involved in traditional publishing. Most of the traditional publishing houses have their own author services which provide a researcher the language editing service, formatting services, data analysis services, and so on based on the plan and payment the researcher has chosen. The higher the payment, the higher the publication support. It is the issue of another debate that getting published in a reputed journal by efforts of an agency providing such author services is how much more ethical is it, and whether it is a form of corruption. As noted by Eriksson and Helgesson (2017),

"Although predatory practices, such as spamming researchers incessantly, charging elaborate fees, or publishing anything against a fee regardless of the quality of the work, are all worthy of criticism, they do not necessarily make the journal applying them predatory." (Eriksson and Helgesson, 2017)

All traditional reputed journals also convince researchers why to publish with them as so-called predatory journals do. Further, a similar observation has been made by Pamukcu Gunaydin and Dogan (2015),

"Many open-access publishers are trustworthy and many are making amateurish mistakes, particularly when they are at the start of entering the publishing market. These are not predatory or fake journals." (Pamukcu Gunaydin and Dogan, 2015)

Masten and Ashcraft (2016) also expressed similar views and equated open access journals with so-called traditional scientific journals and wrote,

"Characteristics of scholarly open access journals are compatible with many characteristics of traditional journals, including the four key criteria of archiving/ preservation, reputable board members, indexing, and peer review." (Masten and Ashcraft, 2016)

When considering predatory journals, it is important to clarify one common misperception that while predatory journals are almost always open access, most open-access journals are far from predatory (Roberts, 2016). Similar observation has been made by other researchers too. Krawczyk and Kulczycki (2021) mention that:

“...the overgeneralization of the flaws of some open access journals to the entire open access movement has led to unjustified prejudices among the academic community toward open access." (Krawczyk and Kulczycki, 2021)

Many researchers have ignored many aspects of scientific publications and indirectly (and maybe unintentionally?) stigmatized journals that have an openaccess policy to be suspected as predatory one. Beall (2017b) mentions, 
"Predatory publishers are essentially counterfeit publishers. They pretend to be genuine scholarly publishers, but they aim really to generate as much revenue as possible from researchers." (Beall, 2017b)

The quality of a journal could not be judged based on the model it has adopted as either pay $\&$ publish or pay $\&$ access. If pay $\&$ publish is enough to suspect a journal for being predatory, then most of the scientific publishers are predatory up to a certain extent. There should be degrees of predation as almost all traditional journals ask some amount from authors to make their articles open for all free of cost and even encourage authors to opt for publication of their article under open access for wider reach. Most of the definitions of predatory journals included the criteria of payment for publication, upon which they have criticized open-access publishers as predatory, and labeled such practice as profit-making for publishers. If the same criteria are applied to traditional journals, the profit is much higher in the pay $\&$ access model than the pay $\&$ publish model. Moreover, a journal asking for one-time fee from the author for a publication, and remaining otherwise free for readers is considered a profit-making journal, then what about those charging readers every time they access that article, either through individual subscription or through an institutional subscription? If the former could be termed as predatory, then why not later could be termed as the Wolfish model? Not asking for APC does not guarantee the quality of the publication. Also, the pay $\&$ access model of scientific articles is not based on universal access; rather these are based on the philosophy that scientific knowledge is only for those who can pay, making science a luxury affair.

The reality behind the wave against so-called predatory journals could be seen from the different perspectives of the market. Usually, the journal publication market is under the control of a few international publishing houses which can be counted on a few fingers. These publishing houses might never wish to allow either open access journals or small-scale local scientific publishers to grow in order to continue their monopoly in publication, maximizing their profit, and they will not wish to lose their potential market in developing countries. Fear of loss of business for them comes from the open-access movement and open-educational resources movement which is trying to break the monopoly of traditional journal publication. Developing an open-access culture strikes the interest of traditional publishers and thus will not be supported at all by them. Beall (2015) mentions that:

\footnotetext{
"authors are now seen as a source of revenue for publishers, and other companies and services are being formed to exploit the author-fee market." (Beall, 2015)
}

Here the question is, when is the author not seen as a source of revenue for publishers? In fact, the supporters of open access community is a result of consistent exploitation of author-fees as well as an access-fee market. The traditional publishing industry is also tailored around exploiting access-fee as well as author-fee markets, otherwise, what is the necessity of author services which are being provided by most of the traditional journal publishers anyway? 


\section{The Issue of Peer-Review and Open Access}

The second issue which characterizes an open-access journal to be called predatory is the diluted process of peer review. It is beyond critique that peerreview is an essential component of a scientific publication. As peer-review is the basis for reliable scholarly dissemination of research, it is, for many, the chief problem presented by predatory journals (Eriksson and Helgesson, 2017). Further, because they (predatory publishers) want to earn money quickly and easily, most predatory journals fail to perform on the single most important element of scholarly communication: peer review (Beall, 2017b). Unfortunately, there is no such tool or device or mechanism available for authors or end-users, other than their own subjective judgments, to cross-check the peer-review claim of a journal being either predatory or non-predatory. If it is true that manuscripts in predatory journals receive only superficial review, then one should find that they are given a stamp of approval even if they contain significant weaknesses (McCutcheon et al., 2016); but the similar is true for those non-predatory scientific journals too. There is a more general problem with false peer reviews. The reputed indexing agency BioMed Central (BMC) discovered in November 2014 that about fifty articles were carrying false reviews (Eriksson and Helgesson, 2017). The issue of peerreview indicates that if the journal (predatory or traditional) says it is peerreviewed, one has to accept that it is. If a journal mentions it is international and it meets the criteria of internationality as per the International Standard Serial Number assigning agency, it is. If merely delayed acceptance, delayed response, and delayed publication confirms that the journal is peer-reviewed, so-called predatory journals will make a delay in publication. It is a criterion that is not objective and can not be assessed and is based upon individual subjective judgment of authors and readers and mostly based upon their intuition. Eriksson and Helgesson (2018) seem right when they suggest that we should stop talking about predatory publishing and start distinguishing between deceptive and lowquality journals (Eriksson and Helgesson, 2018).

Another question that is pertinent here is what role the ISSN agency plays? Asking and assessing the publication policy, publication ethics, and the peerreview process along with a list of members of the editorial board, reviewers, etc., supported by acceptance of editorial board members as well as reviewers might be helpful in controlling such low-quality journals meant only for business. In fact, the information available over the website of the ISSN agency clearly mentioned that the agency can grant, as well as withdraw or decline, the request of an ISSN if the journal does not fulfill the standard as required by the ISSN Agency. As a last comment, Eriksson and Helgesson (2018) mention,

"gathering a wide variety of problems under the broad notion of predatory publishing might cause us to overreact and too easily look at fairly low-cost, open-access journals as all evil: Might the label predatory publishing harm the cause of open access? Or inhibit publishing in developing countries?" (Eriksson and Helgesson, 2018) 
The scientific community must take note of it while discouraging open access initiatives in the name of predatory ones, stigmatizing and victimizing it, either unintentionally or deliberately, labeling it mostly predatory in nature.

\section{Conclusion}

In brief, after critical analysis of the ongoing debate of predatory and nonpredatory journals, it was learned that there is no such standard or universal definition communicating the clear meaning of predatory journals. Also, it is not clear how these journals emerged despite the rigorous process of getting an ISSN prior to starting a new journal. Just because most such predatory journals are freely available over the internet, these could not be termed as an open-access journal because such journals lack the criteria of peer-review which is essential for a publication to be termed as an open-access article/journal or publication. Further, making such comments that predatory journals are freely available and are thus are open-access journals is a way of victimizing and stigmatizing the open-access model. A journal having no proper peer-review and collecting a huge amount as APC is something else, but is not an open-access journal. Thus, one should not equate or label open access journals as predatory journals. Measures need to be taken and policies need to be in place to fight predatory journals, but open-access journals should not be marginalized from the business of publication and should not be victimized by generalizing the predatory word, rather the international scientific community needs to think of distinguishing features and establishing a universally accepted definition of predatory journals and making policies to discourage them.

\section{References}

Bartholomew, R. E. (2014). Science for sale: the rise of predatory journals. Journal of the Royal Society of Medicine, 107(10), 384-385.

Beall, J. (2015). Predatory journals and the breakdown of research cultures. Information Development, 31(5), 473-476.

Beall, J. (2017a). Predatory journals threaten the quality of published medical research. Journal of Orthopaedic and Sports Physical Therapy, 47(1), 3-5.

Beall, J. (2017b). Writer's Forum - Predatory journals, peer review, and education research. New Horizons in Adult Education \& Human Resource Development, 29(1), $54-58$.

Berger, M., Cirasella, J. (2015). Beyond Beall's s list: better understanding predatory publishers. College and Research Libraries News, 76(3), 1-4.

BOAI (2002). Budapest Open Access Initiative. Retrieved from: https://www.budapesto penaccessinitiative.org/. [Accessed 23 October 2021]

Cartwright, V. A. (2016). Authors beware! The rise of the predatory publisher. Clinical and Experimental Ophthalmology, 44(8), 666-668.

Clark, J., Smith, R. (2015). Firm action is needed on predatory journals. BMJ (Online), 350(Mar), 14-16.

Clemons, M., de Costa e Silva, M., Joy, A. A., Cobey, K. D., Mazzarello, S., Stober, C., et 
al. (2017). Predatory invitations from journals: more than just a nuisance? The Oncologist, 22(2), 236-240.

Cook, C. (2017). Predatory journals: the worst thing in publishing, ever. Journal of Orthopaedic and Sports Physical Therapy, 47(1), 1-2.

Duc, N., Hiep, D., Thong, P., Zunic, L., Zildzic, M., Donev, D., et al. (2020). Predatory open access journals are indexed in reputable databases: a revisiting issue or an unsolved problem. Medical Archives, 74(4), 318-322.

Eriksson, S., Helgesson, G. (2017). The false academy: predatory publishing in science and bioethics. Medicine, Health Care, and Philosophy, 20(2), 163-170.

Eriksson, S., Helgesson, G. (2018). Time to stop talking about 'predatory journals.' Learned Publishing, 31(2), 181-183.

Ferris, L. E., Winker, M. A. (2017). Research integrity corner: special issue on predatory journals Review Ethical issues in publishing in predatory journals. Biochemia Medica, 27(10), 279-284.

Krawczyk, F., Kulczycki, E. (2021). How is open access accused of being predatory? The impact of Beall's lists of predatory journals on academic publishing. The Journal of Academic Librarianship, 47(2), 102271.

Manca, A., Moher, D., Cugusi, L., Dvir, Z., Deriu, F. (2018). How predatory journals leak into PubMed. Cmaj, 190(35), E1042-E1045.

Masten, Y. B., Ashcraft, A. S. (2016). The dark side of dissemination: traditional and open access versus predatory journals. Nursing Education Perspectives, 37(5), 275-277.

McCutcheon, L. E., Aruguete, M. S., McKelvie, S. J., Jenkins, W., Williams, J. L., McCarley, N., et al. (2016). How questionable are predatory social science journals? North American Journal of Psychology, 18(3), 427-440.

Moher, D., Srivastava, A. (2015). You are invited to submit... BMC Medicine, 13(1), 1-4.

Narimani, M., Dadkhah, M. (2017). Predatory journals and perished articles; a letter to the editor. Emergency, 5(1), 258-260.

Pamukcu Gunaydin, G., Dogan, N. O. (2015). A growing threat for academicians: fake and predatory journals. Journal of Academic Emergency Medicine, 14(2), 94-96.

Roberts, J. (2016). Predatory Journals: think before you submit. Headache: The Journal of Head and Face Pain, 56(4), 618-621.

Shamseer, L., Moher, D., Maduekwe, O., Turner, L., Barbour, V., Burch, R., et al. (2017). Potential predatory and legitimate biomedical journals: can you tell the difference? A cross-sectional comparison. BMC Medicine, 15(1), 1-14.

Shyam, A. (2015). Predatory journals: what are they? Journal of Orthopaedic Case Reports, 5(4), 1-2.

Swan, A. (2012). Policy guidelines for the development and promotion of open access; 2012. In Technology. UNESCO.

Xia, J. (2015). Predatory journals and their article publishing charges. Learned Publishing, 28(1), 69-74.

Xia, J., Harmon, J. L., Connolly, K. G., Donnelly, R. M., Anderson, M. R., Howard, H. A. (2015). Who publishes in "predatory" journals? Journal of the Association for Information Science and Technology, 66(Jul), 1406-1417. 
